\title{
EDITORIAL
}

\section{Health care the Nordic way}

The Nordic countries demonstrate a way of organising and financing the health care sector that is interesting as a model for other countries at various levels of income. The five articles in this issue of the Nordic Journal of Health Economics originate from a series of exploratory workshops focused on the Nordic health care systems. In contrast to previous literature and thanks to our two Icelandic colleagues, Iceland is included in our Nordic analyses.

The first article (Lyttkens et al.) explores the argument that it is reasonable to talk about a Nordic health care system, in other words, that there are sufficient similarities across the Nordic countries (compared to other OECD countries) to warrant the use of that concept. The similarities appear in the health care sector, but also (and equally importantly) in the social and institutional context in which the health care sector is embedded. The functioning of the health care sector in the Nordic countries is significantly influenced by the fact that the Nordic countries are high-trust and high-tax tax societies in sparsely populated and small open economies.

The following four articles investigate important aspects of the Nordic health care systems. Ásgeirsdóttir and Gerdtham look at health-related behaviour in the Nordic countries (generally better than OECD average). Iversen et al. investigate how different coordination issues are tackled in the Nordic countries, from the allocation of activities across hospitals and to the coordination of care for particular patient groups. Primary care is probably the best example of different approaches in the Nordic countries, and this is detailed in Rose Olsen et al. Finally, the emerging and increasingly important market for complementary voluntary private health insurance in the Nordic countries is documented by Alexandersen et al.

The final paper in this issue is by Peter Smith, who to our great satisfaction accepted the role as external commentator of the Nordic health care system(s) and of our analyses of the Nordic health care sectors. Smith provides a stimulating and knowledgeable overview of the Nordic system and the relationship between the experience of the Nordic countries and that of other high-income countries. Smith concludes that the Nordic countries seem to be doing relatively well in terms of quality in health care and resource use, compared to the OECD in general and compared to a selection of five similar non-Nordic countries (Lyttkens et al.). Consequently the Nordic experience may be of considerable interest to other countries, though there are also specific challenges ahead for the Nordic citizens. For example, waiting times often seem too long for comfort.

The characteristics of the Nordic system is of considerable interest to other countries, for example, the reliance on general government taxation to finance the health care sector and hospitals publicly owned and manned by salaried physicians. Some things are left aside, however, in the five articles. It is with particular interest that I note Smith's observation that the supply of clinical professionals remains to be studied. The challenge to the Nordic system that comes with increased social heterogeneity will be obvious not only on the demand side but also on the supply side of health care. This seems like an important area for future research, perhaps in particular when coupled with the ever increasing possibilities of medical technology and the rising cost of high-quality care. Smith also emphasises the possibilities for interesting research on these issues in the Nordic countries, but also that this research may require some new thinking to secure the availability of relevant data. 
I mentioned in the beginning that the five Nordic papers grew out of a series of exploratory workshops. The whole endeavour was based on a project for which the Nordic Research Council provided an external grant. Consequently, for all the six articles in this issue, we wish to gratefully acknowledge financial support from the Nordic Council (project grant no: 229987/F10).

Finally, I cannot refrain from pointing out that this research project in itself serves as a test of one of the most important premises in our work on the Nordic health care systems: I would not have attempted such an ambitious project if it had not been for my belief in the high level of trust and trustworthiness in the Nordic countries. All Nordic colleagues that I contacted have supported the project, time margins have been tight but deadlines have been kept (almost meticulously), and participants in the project have travelled to our workshops spread over three of our countries on tight time and money budgets. As project leader, I am very grateful to them and to our UK participant Matt Sutton who invariably provided important and constructive input to our discussions. Finally, Anna Welander provided essential administrative and scientific assistance to the project, and the staff and the reviewers of the Journal have been very helpful.

Carl Hampus Lyttkens

Guest editor 